\title{
Suitability Evaluation of Urban Material Storehouse
}

\author{
Ziming Song, Peng Chen \\ College of Tourism and Geographical Science, Jilin Normal University, Siping 136000,China
}

\section{城市物资库适宜性评价}

宋紫铭, 陈鹏

吉林师范大学旅游与地理科学学院, 吉林 四平 136000 , 中国

\begin{abstract}
In recent years, urban emergencies emerge in an endless stream, and how to provide relief supplies at the first time after the disaster has become one of the key problems in response to urban emergencies. This study takes Nanguan District of Changchun as a research and demonstration area and GIS technology as support means, and analyzes the optimal layout of urban material storage. Firstly, each evaluation index is established according to relevant documents, and then AHP (Analytic Hierarchy Process) method is used to determine the weight of each evaluation index. Finally, with GIS technology as the support means, the appropriate level of urban material storehouse construction land use is analyzed by the weighted comprehensive evaluation method. The result of optimized layout can provide decision support for relevant departments of Changchun municipal government.
\end{abstract}

Keywords:City material storehouse; AHP; weighted comprehensive evaluation method

\section{摘要}

近年来，城市突发性事件层出不穷， 如何在灾害发生后第一时间提供救援物资 成为应对城市突发事件关键问题之一。本 研究以长春市南关区为研究示范区, GIS 技
术为支持手段, 分析了城市物资库优化布 局。首先根据相关文件确立各个评价指 标, 再运用 AHP (Analytic Hierarchy Process）方法确定各个评价指标的权重, 最后以 GIS 技术为支持手段, 运用加权综 合评价法分析出城市物资库建筑用地适宜 级别。优化布局的结果可为长春市政府相 关部门提供决策支持。

关键词: 城市物资库; AHP; 加权综合评 价法

\section{1. 引言}

城市是一个国家或地区的政治、经济和文 化中心, 人口、贸易、运输、建筑和其他 现代要素的高度集中地。人口增长和城市 化水平的快熟提高导致了城市的快速扩张 [1-2], 现如今, 各种灾害在城市中频频发 生, 所造成的各种损失不计其数, 所以现 如今的热点是如何及时、准确、快速的从 城市物资库调运物资到受灾地区。物质资 源的作用在于直接满足社会众的物质与安 全需求 $[3]$ 。

我国国土面积大、人口多且分布不均 [4], 各城市所受城市灾害类型不同, 且每 次所受到的灾害大小也不同, 最重要的是 我国目前中央级的救灾物资储备库虽然已 经由 10 个增加到 24 个, 但他们到各个城 市的距离不一, 有的十分远, 无法快速调 运物资到受灾地区, 不能达到很好的救援 效果。因此, 在一些地区建立一定数目的 城市物资库就成了势在必行的事情。 
本文以吉林省长春市南关区为例, 在 民政部颁发的救灾物资储备库建设标准的 基础上, 以及各种社会经济因素如交通区 等, 建立相应的指标体系, 并且应用 GIS 技术对长春市城市物资库进行适宜性评 价, 从而已达到为长春市开展相关工作提 供便利, 也对我国该领域的研究成果进一 步拓展。

\section{2. 研究区概况}

长春市位于中国东北地理中心, 享有 “北国春城”之美称, 是首批全国城市设 计试点城市, 是中国十大科研第六城市。 南关区是长春市的一个下辖区, 是长春市 的南大门, 位于长春市区东南部。长春市 南关区位于北纬 $43^{\circ} 80^{\prime}$ 至 $43^{\circ} 92^{\prime}$, 东经 $125^{\circ} 35^{\prime}$ 至 $125^{\circ} 37^{\prime}$ 之间 (见图 1), 处 于长春市中南部。南关区实际管辖面积为 80.95 平方公里, 其中城区面积 23.85 平方 公里, 常驻人口 64 万人口, 地区生产总值 完成 242 亿元。南关区近年来致力于旧城 改造和新城开发, 先后建成多幢商务楼 宇、现代化办公楼、中高档住宅小区等。 该区发生事故大, 人口较为密集, 一旦发 生城市突发事故, 那么造成的损失也是巨 大的。

\section{3. 究方法与数据}

\section{1 研究方法}

\subsection{1 加权综合评价法}

加权综合评价法是指将评价最终目标 分为若干层次和若干指标, 根据 AHP 法求 出的不同指标权重进行综合评价 [5]。

\section{1 .2 叠加分析}

在 GIS 中占据非常重要的空间分析功 能之一就是叠加分析, 指的是在统一的空 间参照系统条件下, 对同一地区的两个数 据的图层进行叠置, 以产生新的空间数据 的过程。

\section{1 .3 重分类}

重分类一般起到简化数据的作用。如 高程信息, 将所有高程从小到大排列, 然 后按照分位数、自然间断点分级等方法将 其分为几个等级, 每一等级对应一定的高 程范围。然后按照一一对应的方式, 改变
个栅格的数值。

\subsection{4 欧氏距离}

欧氏距离属于空间分析中的距离工 具, 它是一个用距离表示每个像元到一个 数据源或一组数据源之间的关系。

\section{1 .5 分位数法}

分位数法是对数据进行重分类时所选

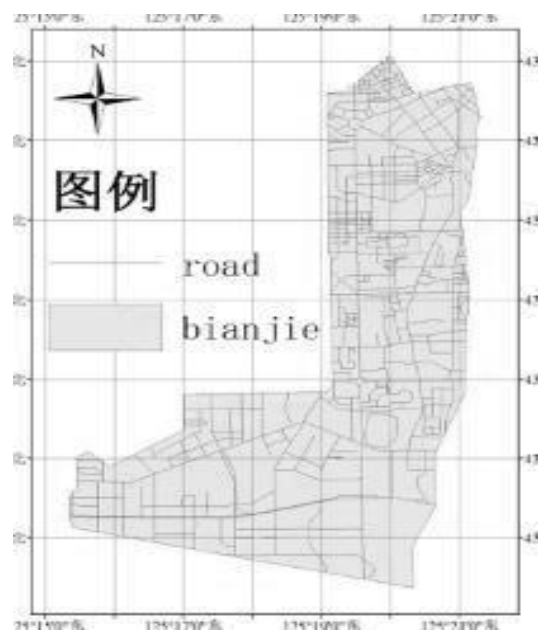

图 1 长春市南关区位置示意图

定的一种分类方法, 一般呈线性分布的空 间数据适用于使用分位数法, 没有过多或 者过少的类, 也没有空类。经过分位数法 处理的要素, 每个类中要素的数量是相等 的。

\section{1 .6 自然间断点分级法}

自然间断点分级法也是对数据进行重 分类时所选定的一种分类方法。该方法是 一种地图分级算法, 认为数据本身有断 点, 可利用数据这一特点分级, 且类别以 数据中固有的自然分组为基础。

\section{2 数据}

本文研究区域的矢量数据来自于笔者 使用 ArcGIS 对长春市南关区影像数字化得 到的图; 所用的社会经济数据是来自吉林 省长春市南关区的统计年鉴; 本文在当地 交通部门收集了长春市南关区的交通数 据; 以及在地理空间数据云中收集了长春 市南关区的遥感影像。 


\section{4. 城市物资库建设原则}

根据 2009 年 1 月民政部颁布的《救灾 物资储备库建设标准》, 并且结合研究区 发布的城市规划, 遵循储存安全、调运方 便原则, 并且要满足以下的要求 [6]:

(1) 地势较高, 工程地质和水文地质 条件较好, 根据 DEM 影响的数据选取地势 较高的位置, 但是也不能过高, 运输不方 便, 降低救援效果, 而且如果地势过于高 的, 对于建筑会产生一定的困难, 从而增 加过多的费用。城市物资库的地势要相对 平坦, 视野相对开阔。

(2) 物资库的建立一般要离河流远一 些, 且不适宜处在水网较为密集的地方。

(3) 市政条件较好, 交通运输便利, 物资库内外道路应通畅便捷, 市级及市级 以上救灾物资储备库宜临近铁路货站或高 速公路入口。便宜的交通不仅可以加快在 危险发生后物资的快速抵达, 还可以在道 路拥挤时具有多项选择, 因此在对城市进 行道路分析时, 应选择道路网较为密集的 地方。

(4) 物资库的建立要建立在远离火 源、易燃易爆厂房和库房等, 像是加油 站、淀粉厂、汽修厂附近都不适宜建立物 资库, 也要远离污染源, 以便对物资库存 储的物资造成污染。

\section{5. 评价指标体系建立}

影响城市物资库选址的因素较多, 综 合考虑研究区内建设用地利用的主要特 点、数据可得性及指标设计和理性, 参考 相关研究成果 [7], 根据科学性、典型性和 代表性原则, 笔者确定了评价的指标体系 由地形因素、河流因素和社会经济因素组 成。

\section{1 地形因素}

地形因素以高程、、坡度为评价指 标。地形因素对物资库的建立的预算具有 很大的决定因素, 对于物资库的运输也有 影响。因此, 地形因素对城市物资库的适 宜性评价有着至关重要的影响。

\section{2 河流因素}

河流因素以河流、河网密度为评价指 标。近些年, 国家对于水资源的保护越来 越看重, 为了更好的保护水资源, 很多厂 房都禁止建立在河流旁, 物资库通常也不 设立在河流周围。

\section{3 经济社会因素}

社会经济因素以交通条件、建筑密 度、易燃易爆物厂房为评价指标。其中易 燃易爆物厂房代指具有危险性的区域。近 些年, 人民的生活水平不断地提高, 汽车 已经成为家庭生活的必需品, 电视机、洗 衣机等各种电器进入到千家万户, 各种新 型电子设备都属于一旦发生火灾会加大火 势的物品。且随着城市化的进程, 城市的 人口过于集中, 导致城市的建筑越来越 高、越来越多, 城市建筑密度过大, 这些 都属于灾害频繁发生的区域。影响城市物 资库适应性评价的又一个重要因素就是交 通运输, 交通运输还可以表示一个城市物 资库有效的辐射范围。交通的发达程度直 接关系到救援的速度, 和资源抵达量。

\section{4 评价指标的确定}

评价指标权重确定则采用层次分析法 加以测算, 保障评价指标权重确定的科学 性和准确性。主要邀请了土地、生态、环 境领域相关专家和当地相关机构技术人员 对各层指标的相对重要性进行两两比较、 判断, 并保持判断矩阵的一致性 [8-10], 最后的得出各个指标的权重值。

表 1 物资库选址适宜性指标与权重

\begin{tabular}{ccc}
\hline 影响因素 & 评价指标 & 权重 \\
\hline 地形因素 & 高程 & 0.1851 \\
& 坡度 & 0.1474 \\
河流因素 & 距河流距离 & 0.0931 \\
& 河网密度 & 0.0465 \\
社会经济因素 & 交通条件 & 0.1641 \\
& 建筑密度 & 0.1034 \\
& 易燃易爆物厂房 & 0.2604 \\
\hline
\end{tabular}




\section{6. 城市物资库选址适宜区确定}

\section{1 地形因素}

城市物资库的建筑用地首先要考虑平 坦开阔的地方, 这样通风性良好, 对于物 资的储存有极大的好处, 有利于交通网的 建设, 可以快速运输物资, 且建设物资库 的预算会比较低。将长春市南关区的 DEM ( Digital Elevation Mode1) 加载 到 ArcGIS 中, 使用栅格表面分析工具坡度, 即可直接提取长春市南关区的坡度。再对 坡度进行重分类处理, 采用分位数法分为 四个等级; 对高程使用重分类, 也采用分 位数法分为四个等级。最后对三张图进行 加权叠加, 对处理出的图像再对其进行重 分类, 采用分位数法分为地形适宜区、地 形较适宜区、地形较不适宜区、地形不适 宜区（如图 2）。

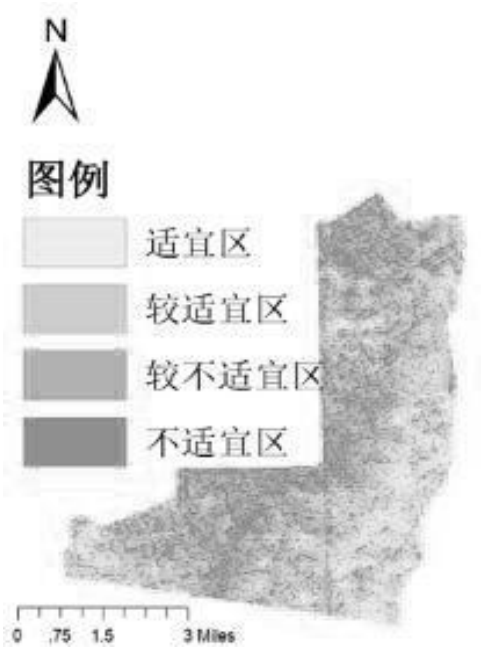

图 2 地形因素适宜性

\section{2 河流因素}

城市物资库的建设不适宜建立在距离 河流近的地方, 也不适宜建立在河网密度 大的地方。建设时易对河流造成污染, 且 若离河流太近, 物资不易存储 [11]。对长 春市南关区的遥感影像进行数字化处理, 在图像中数字化出水域、建筑、道路等信 息。对水域数据使用空间分析中得欧氏距
离, 对得出的数据进行重分类, 采取自然 点间断法。再对数字化的水域提取中心 点, 对其进行 IDW (Inverse Distance Weighted), 之后再进行重分类, 采用分位 数法。最后对两张图进行加权叠加, 对处 理出的图像再对其进行重分类, 采用分位 数法分为四个等级（如图 3)。

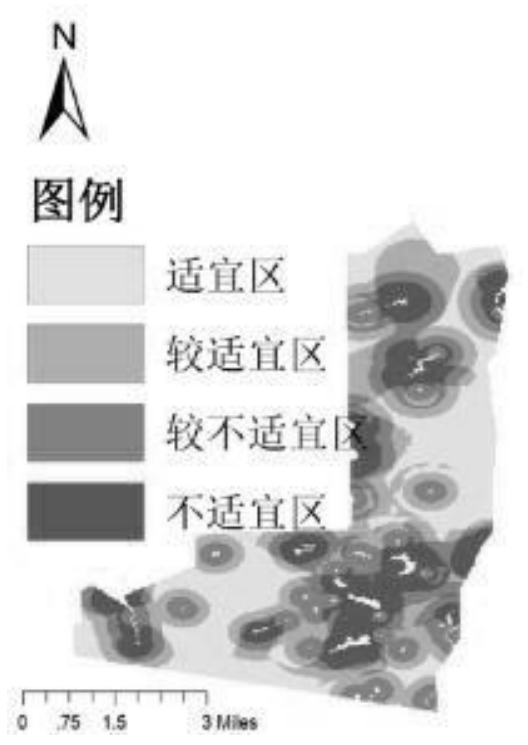

图 3 河流因素适宜性

\section{3 社会经济因素}

时间应为应急救援的约束条件, 在突 发性灾害发生时, 物资能到达的最短时间 往往决定着灾害发生后可减少得不良影 响, 这就要求我们在建立物资库时考虑道 路的状况。因此, 为了具有更多的选择城 市物资库要建立在交通网较为密集的地 方。对交通数据使用空间分析中的线密度 分析, 得出的数据在进行重分类, 采取分 位数法。在城市中建筑群密集的地方, 往 往伴随着高集中的人口, 在建筑高度集中 的地方虽然不适宜建城市物资库, 但物资 库却要建立在其旁边。最后对三张图进行 加权叠加, 对处理出的图像再对其进行重 分类, 采用分位数法分为社会经济适宜 区、社会经济较适宜区、社会经济较不适 宜区、社会经济不适宜区（如图 4)。 


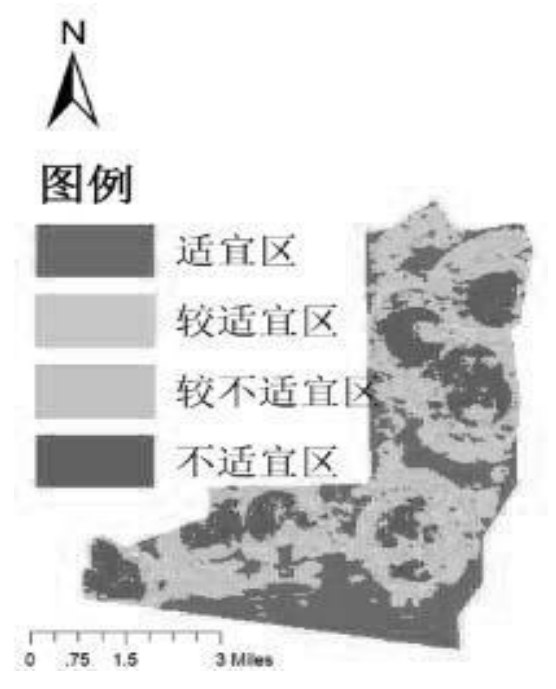

图 4 社会经济适宜性

\section{4 加权综合法}

加权综合法的内容是指, 对影响某个 事件的所有影响因素乘以它们各自的权重 最后相加, 其中影响因素的权重等于各个 评价指标乘以各自的权重最后相加。

$$
\begin{gathered}
f=\sum_{i=1}^{n} w_{i} \times \alpha_{i} \\
f_{1}=\alpha_{1} w_{\alpha 1}+\alpha_{2} w_{\alpha 2} \\
f_{2}=b_{1} w_{b 1} b_{2} w_{b 2} \\
f_{3}=c_{1} w_{c 1}+c_{2} w_{c 2}+c_{3} w_{c 3}
\end{gathered}
$$

式子（1）中 i 为影响因素的编号; wi 表示 第 $i$ 项指标的权重数值; ai 表示第 $i$ 项指 标的数据值。（2）中 a1、a2 分别代表高 程、坡度三个评价指标, wa1、wa2 分别代 表高程、坡度三个评价指标的权重数值。

（3）中 b1、b2 分别代表距河流距离, 和 河网密度两个评价指标, wb1、wb2 分别代 表距河流距离, 和河网密度两个评价指标 的权重数值。（4）中 c1、c2、c3 分别代 表交通条件、建筑密度、易燃易爆物厂房 三个评价指标, wc1、wc2、wc3 分别代表交 通条件、建筑密度、易燃易爆物厂房三个 评价指标。

\section{5 城市物资库适宜区}

最后根据三个影响因素各自的指标权 重, 利用 ArcGIS 中的空间分析功能进行加 权叠置分析, 测算出长春市南关区城市物 资库适宜性评价的总体情况。再对得到的 数据进行重分类, 采取分位数法, 将其分 为物资库适宜区、物资库较适宜区、物资 库较不适宜区、物资库不适宜区 (如图 5)。

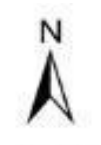

\section{图例}

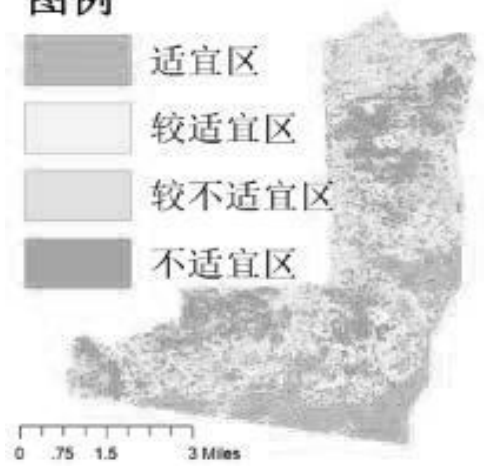

图 5 城市物资库选址适宜区

\section{7. 结论}

随着城市化进程的不断加快, 城市人 口越加密集, 各种突发状况层出不穷。建 立城市物资库成为当下较为重要的事情之 一。据此, 利用 GIS 技术和加权综合法建 立了长春市南关区城市物资库适宜性评价 模型。基于 GIS 的城市物资库适宜性评 价, 实现了城市物资库适应性评价结果在 空间上的显示。评价结果显示出长春市南 关区城市物资库适宜性评价不同适应性级 别的空间分布特点和一定的限制因素, 南 关区中部地区和下部地区适宜建立城市物 资库, 上部地区和中下部地区不适宜建立 城市物资库。但是本文在建立指标体系是 过于主观, 导致模型运算结果具有一定的 误差。

本研究可以给予政府在建立城市物资 
库上一定的数据和理论支持, 也可以为其 他类似城市建立物资库适应性评价提供参 考和借鉴。

\section{致谢}

本研究得到了国家社会科学基金项目 (41501557) 的资助。

\section{参考文献}

[1] 季宁.城市应急管理中的物资调度优化 研究. 西安理工大学, 2009 .

[2] 梁武,陈美球, 黄宏胜, 罗志军. 鄱阳湖滨 湖地区人口城镇化与土地城镇化协调 性研究.土地经济研究, 2016(01):47-63.

[3] 陆大道, 姚士谋. 中国城镇化进程的科学 思辨.人文地理,2007(04): $1-5+26$.

[4] 杜宝贵,张韬. 正确认识公共危机管理中 的几个关系. 东北大学学报(社会科学 版),2003(05):361-363.

[5] 王畔, 陈丽, 陈圼, 薛漫清, 梁庆. 多指标综 合评价方法及权重系数的选择. 广东药 学院学报,2007(05):583-589.

[6] 陈鹏, 张继权, 孙港悦, 张立峰, 刘家福. 城 市火灾应急物资库优化布局.消防科学 与技术,2015,34(01):110-113.

[7] 王海鹰,张新长,康停军.基于 GIS 的城市 建设用地适宜性评价理论与应用. 地理 与地理信息科学,2009,25(01):14-17.

[8] 刘朝亮. 层次分析法在农业系统中的应 用研究.广东农业科学,2013,40(13):228232.

[9] 柴仲平,王雪梅,蒋平安.基于 AHP 决策 分析方法的石河子市土地适宜性评价. 国土与自然资源研究,2009(04):38-39.

[10] 石振武,赵敏.运用层次分析法确定指标 的权值.科技和产业,2008(02):23-25.

[11]Chen P, Zhang J Q, Sun Y Y, Liu X J. Wargame Mapping and Implementation for Emergency Evacuation of Residents in Urban Waterlogging Disaster .Journal of Risk Analysis and Crisis Response, 2018, 8(1): 43-51. 